\title{
Perfil Dos Pacientes Com Tuberculose No Município De Santa Cruz Do Sul No Ano De 2013
}

\author{
Chaves, J.; Fernandes, R.; Ourique, F.; Pilletti, K.; tomilin, B.S.; Brun, D.V. \\ Rodrigues, M.T.; \\ Apresentador: Jéssica Chaves
}

\section{Resumo}

Introdução: A tuberculose (TB) é das doenças infecciosas mais prevalentes em todo o mundo, responsável pela morte anual de mais de dois milhões de pessoas. A doença é causada pelo Mycobacterium tuberculosis, podendo apresentar comprometimento pulmonar ou extrapulmonar. O Rio Grande do Sul é um dos estados com a maior taxa de tuberculose do país, e Santa Cruz do Sul está entre os municípios prioritários do estado para o controle da tuberculose devido as altas taxas apresentadas. Objetivo: Analisar o perfil epidemiológico dos pacientes com tuberculose no município de Santa Cruz do Sul/RS no ano de 2013. Método: Estudo descritivo, transversal, retrospectivo. Foram revisados os prontuários de pacientes atendidos no ambulatório de tuberculose do Hospital Santa Cruz, do município de Santa Cruz do Sul (SCS), no ano de 2013. As variáveis analisadas foram sexo, idade, comorbidades e sintomas mais prevalentes. As variáveis categóricas foram expressas em porcentagens do total e as contínuas em médias e desvios-padrão. Os dados foram tabulados no programa Excel. RESULTADOS: Foram atendidos 91 pacientes no ambulatório de tuberculose no ano de 2013. Desses, 64,84\% eram do sexo masculino e $35,16 \%$ eram do sexo masculino. De todos os casos, $83(91,21 \%)$ eram casos novos, resultando em uma incidência de 80/100.000 habitantes. A forma pulmonar foi a mais frequente, $73,6 \%$ dos casos, $9,89 \%$ eram extrapulmonar e $2,2 \%$ tinham pulmonar e extrapulmonar. Do número total, $29,67 \%$ eram presidiários, enquanto outros $12,66 \%$ tinham diagnóstico de AIDS. Tabagismo esteve presente em $41,67 \%$ dos pacientes e $17,65 \%$ eram usuários de drogas ilícitas. Tosse com expectoração foi o sintoma mais frequente com $60,44 \%$, e o tempo médio de evolução até o diagnóstico foi de nove semanas. Perda de peso $(51,65 \%)$, sudorese noturna $(45,05 \%)$, dispneia $(26,3 \%)$, dor torácica $(32,2 \%)$, astenia $(30,7 \%)$ e febre vespertina $(32,9 \%)$ foram outros sintomas referidos. Conclusões: Os altos índices relacionados a tuberculose no município devem refletir em medidas eficazes para o combate a doença na cidade, melhorando a adesão da população ao tratamento, e auxiliando no rastreamento de novos casos. O tratamento precoce da doença, e a investigação de contatos é fundamental para a queda dos índices.

\section{Referência:}

Chaves, J.; Fernandes, R.; Ourique, F.; Pilletti, K.; tomilin, B.S.; Brun, D.V. Rodrigues, M.T.; Perfil Dos Pacientes Com Tuberculose No Município De Santa Cruz Do Sul No Ano De 2013. In: II Congresso Brasileiro de Medicina Hospitalar - II CBMH [= Blucher Medical Proceedings, vol.1, num.5] São Paulo: Editora Blucher, 2014. p.59

DOI 10.5151/medpro-II-cbmh-055 